\title{
Chapter 10 \\ Integrating Avoided Emissions in Climate Change Evaluation Policies for LDC: The Case of Passive Solar Houses in Afghanistan
}

\author{
Yann François and Marina Gavaldão
}

\begin{abstract}
In many Least Developed Countries, the minimum level for basic services like energy access is not reached. In the cases of long-term investment in carbon intensive technologies, the expansion of basic services is likely to carry with it a significant increase in GHG emissions. This chapter discuss the importance of accounting for these avoided emissions through the case study of the Passive Solar Houses (PSH) in Afghanistan.

In Kabul winters are cold and $48 \%$ of households cannot afford enough fuel to heat their house. To reduce fuels expenses and improve living conditions, the NGO GERES is supporting local artisans to disseminate a PSH model made of a veranda built on the south-facing part of the house to conserve the sun energy captured and stored in the walls. During the 2013-2014 winter, the fuel consumption and indoor temperature of PSH and control houses were monitored to assess the impact of the technology.

The results show an energy saving of $23 \%$ resulting in annual greenhouse gases emission reduction of $0.37 \mathrm{tCO}_{2} \mathrm{e} /$ year as well as an average indoor temperature increase of $1.43{ }^{\circ} \mathrm{C}$ to reach $18.22{ }^{\circ} \mathrm{C}$. Then, a regression model was developed to estimate the emissions that would have occurred if the control group had reached the same indoor temperature than the PSH and, in a second scenario, the minimum indoor temperature of $18{ }^{\circ} \mathrm{C}$ recommended by the WHO. For both scenario, the avoided emission represent approximately half of the total climate change mitigation impact with $0.40 \mathrm{tCO}_{2} \mathrm{e} /$ year and $0.34 \mathrm{tCO}_{2} \mathrm{e} /$ year respectively.
\end{abstract}

Keywords Climate change mitigation • Suppressed demand • Avoided emission • Passive solar houses • GERES • Afghanistan

Y. François $(\bowtie) \cdot$ M. Gavaldão

GERES - Group for the Environment, Renewable Energy and Solidarity, Aubagne, France

e-mail: y.francois@geres.eu; m.gavaldao@geres.eu 


\subsection{Introduction}

Globally, the International Energy Agency (IEA) estimates that 1.3 billion people still live without access to electricity and that 2.6 billon are still reliant on biomass for cooking. ${ }^{1}$ There is a staggering inequality in access to services and in the quality of services between rich and poor societies - the poorer three quarters of the world's population use only $10 \%$ of global energy. ${ }^{2}$ Lack of access to minimum levels of basic services is a serious barrier to socio-economic development and progress toward the Sustainable Development Goals (SDG). ${ }^{3}$ While imperative, costeffective expansion of minimum services throughout the developing world is likely to carry with it a significant increase in greenhouse gas (GHG) emissions. In the cases of the development of infrastructures, institutions and cultural practices based on carbon intensive development, the achievement of the SDG could come with a "carbon lock-in" inhibiting a future switch towards low-carbon technologies. 4

Therefore the integration of the expansion of basic services into the climate change evaluations is crucial. The latent demand for basic services that is "suppressed" due to barriers such as low income, weak infrastructure and inadequate access to technology have to be measured and accounted in the decision making process. Pure mitigation instruments that only focus on reducing emissions and not on avoiding emissions are therefore likely to have minimal impact in the long-term for developing countries and offer no incentives for alternative "cleaner" development pathways to the poorest.

In many Least Developed Countries (LDC), the low level of historic emissions means that there is little $\mathrm{CO}_{2}$ emissions to reduce, rendering the gains from resultbased finance mechanisms like the Clean Development Mechanism (CDM) marginal or negligible. To foster the achievement of the sustainable development objectives of the CDM, the concept of "suppressed demand" has been integrated in some of the methodologies allowing to account for minimum services for the baseline GHG emission levels. In this case, instead of the historical emissions, the baseline scenario would account for the GHG emissions if the minimum level for basic services such as energy access, clean water or sanitation was reached. The baseline emissions may be calculated using the baseline technologies in a case where the barrier to meet the minimum level is the cost of operation of the technology like fuel consumption, or new technologies corresponding to the minimum level of services in contexts where the service is available. The determination

\footnotetext{
${ }^{1}$ WEO, Would Energy Outlook 2012 (Paris, France: International Energy Agency, n.d.), http:// www.iea.org/publications/freepublications/publication/WEO2012_free.pdf.

${ }^{2}$ Summary conclusions of the Vienna Energy Forum, June 2011

${ }^{3}$ United Nations, "Resolution Adopted by the General Assembly on 25 September 2015 - 70/1. Transforming Our World: The 2030 Agenda for Sustainable Development.," 2015, http://www.un. org/ga/search/view_doc.asp?symbol=A/RES/70/1\&Lang=E.

${ }^{4}$ Gregory C. Unruh and Javier Carrillo-Hermosilla, "Globalizing Carbon Lock-In," Energy Policy 34, no. 10 (July 2006): 1185-97, doi:10.1016/j.enpol.2004.10.013.
} 
of the minimum levels (minimum energy consumption, daily amount of clean water per capita etc.) and the corresponding GHG emissions level can be challenging, this is the case for the housing sector with the indoor temperature.

According to IPCC's latest report, ${ }^{5}$ in 2010 , buildings accounted for $19 \%$ of the GHG emissions. This same report highlighted the need for scaling up low-energy demand housing systems in LDCs. Low-energy buildings aim to achieve minimum service level without relying on energy-intensive equipment for heating or cooling to avoid a locking in carbon-intensive buildings for several decades. In order to support climate change policies, the evaluation of housing projects in LDCs should integrate this potential carbon-locking and therefore assess the impact of low-energy housing systems using the suppressed demand. But the minimum level for indoor temperature is difficult to estimate as it is highly context specific. Globally, the minimum indoor temperature recommended by the $\mathrm{WHO}$ is $18{ }^{\circ} \mathrm{C}$ with up to $20-21{ }^{\circ} \mathrm{C}$ for more vulnerable groups, such as older people and young children. ${ }^{6}$

Achieving sustainable development in the housing sector of cold regions like Afghanistan requires important improvement of the indoor temperature while mitigating the emissions of the business-as-usual technologies and practices. Therefore the evaluation of the climate change impact of projects in the housing sector of cold regions should also account for the avoided emissions of the intervention compare to the business-as-usual development pathway in addition of the actual emission reduction. This study presents an application of the suppressed demand approach for the housing sector in a difficult context through the case study of the Passive Solar Houses project in Afghanistan. This case study presents the importance of accounting for the avoided emissions when minimum service level are not reached due to incomes barriers but also the methodological challenges of estimating the emissions to reach the same level of service using baseline technologies.

\subsection{Approach}

All over Afghanistan, winters are severe and access to sufficient fuel is a challenge. Most of the households rely on biomass fuels like wood, sawdust or cow dung or mineral coal for heating. In Kabul, energy expenses represent roughly $20 \%$ of households' annual expenses with $6 \%$ only for heating. These fuel expenses are

\footnotetext{
${ }^{5}$ O. Lucon et al., "Buildings," in Climate Change 2014: Mitigation of Climate Change. Contribution of Working Gourp III to the Fifth Assessment Report of the Intergovernmental Panel on Climate Change (United Kingdom, New York, USA: Cambridge University Press, 2014), 671-738, https://www.ipcc.ch/pdf/assessment-report/ar5/wg3/ipcc_wg3_ar5_chapter9.pdf.

${ }^{6}$ WHO, "Health Impact of Low Indoor Temperatures" (Copenhagen: Would Health Organization - Regional Office for Europe, 1985), http://www.theclaymoreproject.com/uploads/associate/365/ file/Health\%20Documents/WHO\%20-\%20health\%20impact\%20of\%20low\%20indoor\%20tem peratures $\% 20 \% 28 \mathrm{WHO} \% 201985 \% 29$.pdf.
} 
particularly important during the winter when incomes are at the lowest and goods prices like food or gas for cooking are at the highest. According to GERES survey, $15 \%$ of households contract debts partly or totally to purchase fuel and $48 \%$ of the household report difficulties to meet their energy needs. Thermal comfort during winter months remains very problematic as the current levels of indoor temperature do not reach the WHO recommended threshold of $18{ }^{\circ} \mathrm{C}$ minimum service level.

In order to improve the thermal comfort during the winters while contributing to climate change mitigation, GERES - Group for the Environment, Renewable Energy and Solidarity, French NGO working in Afghanistan since 2002, has developed and transferred to local entrepreneurs the Passive Solar Housing technology. Passive Solar Housing construction design rely on collecting, storing and distributing solar energy during the winter without any mechanical or electrical equipment. The GERES housing innovation is comprised of a veranda with a wooden frame and plastic sheeting added to the south-facing part of the house. The air inside the veranda is heated during the day by the sun's radiation. By keeping an enlarged window open between the veranda and the house, the warm air is transmitted to the room. At night, the window is closed and curtains are drawn in order to keep the heat inside the room. In addition, the veranda also provide an extra warm room during the day for housework and social events for a very affordable cost (Fig. 10.1).

In 2012, GERES started a 3 year project with funding from the Agence Française de Développement (AFD) and Fondation Abbé Pierre to support local artisans for the wide dissemination of PSH in Kabul. During the winter 2012-2013, a Socio-Economic Assessment of Domestic Energy Practices (SEADEP) survey was conducted to assess the socio-economic and energy consumption profile of households of Kabul. During the following winter, between 2013 and 2014, a monitoring campaign was conducted in Kabul, with the objective of assessing the impacts of PSH technologies on livelihoods and GHG emissions. Two groups of houses each (non-PSH and PSH) were monitored during 8 weeks, indoor and outdoor temperatures were measured using data loggers and fuel consumptions were recorded daily.

Using these data, the impact of the PSH technology in terms of indoor temperature and energy consumption has been assessed to determine the energy efficiency of the PSH compare to the non PSH. Then, using the suppressed demand approach a regression model has been built to assess the GHG emissions that would have occurred if the same indoor temperature was reached using technologies in non PSH. This case study illustrate the importance as well as the limitations of applying the suppressed demand in the housing sector in LDC.

\subsubsection{Sampling and Data Collection}

The houses selected for the study are located in three police districts in the southern part of Kabul and spread from central part of the city to its outskirts, including semi- 


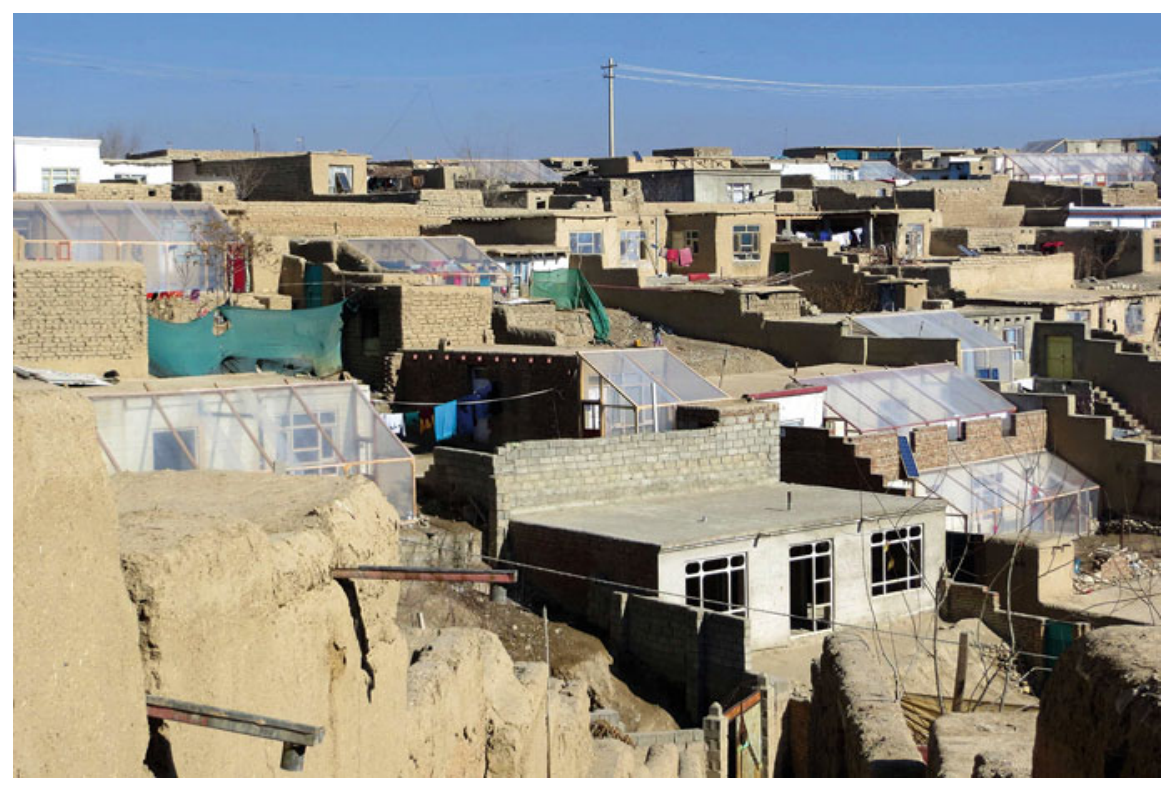

Fig. 10.1 The Passive Solar House (PSH) technology in Kabul

rural areas with agricultural activities. No significant differences appear between the districts that are all characterized by internal heterogeneity: planned and unplanned areas, individual and vertical housing, rich and poor areas. Most residential areas of these districts are occupied by houses built according to the traditional Afghan pattern in mud or cooked bricks, with flat roofs, one to three living rooms, a yard, and the house facing south whenever possible. Therefore, $75 \%$ of the houses in these three districts match GERES' technical requirements for the construction of verandas (South-oriented houses, no direct obstruction and shadow, more than $3 \mathrm{~m}$ in front of the house).

The winter monitoring lasted for an overall period of 8 weeks, from 5 December 2013 to 5 February 2014.

Two groups of houses are classified by type:

- Type 1: Control group - Houses not equipped with the veranda PSH system

- Type 2: Treatment group - Houses equipped with veranda PSH system

To assess the impact of the PSH technology, 13 houses of Type 2 equipped with the PSH are compared with 13 houses of Type 1 selected as a control group. The house were strictly selected using the SEADEP database according the number of heated family room (only houses with one family room were selected), its size and orientation, the household socio-economic profile and energy consumption practices criteria. The house construction plans were survey by GERES technician to insure an unbiased comparison between the two groups of houses. Both PSH and 
non PSH used traditional heating devises ("bukhari") along with wood, coal, sawdust or other fuels like cow dung, shells or cardboard.

The main data collected during the study were the fuel consumption (collected once per day, five times a week) and the indoor and outdoor temperature collected using thermometers with data-loggers.

The thermometers were positioned based on the following criteria:

- Thermometers measuring indoor temperature

- Room: main family room (heated room)

- High: $50 \mathrm{~cm}$ from the ceiling

- Opposite to the heating system (at least $3 \mathrm{~m}$ from the heating system)

- Protected from direct sunrays

- Not close to the windows or doors (at least $1.5 \mathrm{~m}$ from windows and doors)

- Protected to any activity to not be disturbed or damaged

- Thermometers measuring outdoor temperature

- On outer north face of houses

- Not easily accessible (Height: at least $2 \mathrm{~m}$ )

- Protected from snow and rain (below roof overhang)

Only the fuel consumption of the devises situated in the main family room was recorded. Fuel was not provided to households as it can promote overconsumption, household were using their own fuels and a stock was made close to the heating devise that was monitored. The remaining stock of fuel was monitored every day before refilling the stock to insure that the stock was sufficient to support the household energy needs.

\subsubsection{Data Analysis}

Once the data were collected, the fuel consumption and temperature records were cleaned and treated.

\subsubsection{Fuel Consumption and Temperature Data Treatment}

The daily fuel consumption monitored in kilogrammes has been transformed in $\mathrm{kWh}$ and the consumption of all fuels was summed to get an average energy consumption per week. 


\section{Equation 10.1: Calculation of the Weekly Energy Consumption}

Weekly Consumption $(k W h)=\sum_{d=d a y}\left(\sum_{n=f u e l}\right.$ DailyConsumption $\left.(k g)_{n, d} \times N C V_{n}\right)$

The outdoor temperature data collected by the thermometers and data loggers situated outside the house has been transformed into Heating Degree Day (HDD) and summed for each week of measurement. The HDD is a measurement designed to reflect the demand for energy needed to heat a building. It is calculated by counting the missing degrees to reach a comfort temperature. The comfort temperature has been determined at $18{ }^{\circ} \mathrm{C}$ and the HDD18 (explain abbreviation) is calculated as follow:

\section{Equation 10.2: Calculation of the Weekly Heating Degree Day Value}

$$
\text { WeeklyHDD18 }=\sum_{d=d a y} 18-\overline{\text { Daily Temperature }_{d}}
$$

Similarly the indoor temperature data collected by the thermometers and data loggers are used to calculate the weekly average indoor temperature.

Based on these data first analysis of the differences in energy consumption and HDD18 are available between PSH and non-PSH.

\subsubsection{Greenhouse Gas Calculation}

The GHG emissions were calculated from the energy consumption using the Gold Standard GHG calculation methodology "Technologies and practices to displace decentralized thermal energy consumption ${ }^{7}$ " and IPCC emission factors. ${ }^{8}$ For biomass fuels, the calculation of the fraction of non-renewable biomass (fNRB) was based on the Gold Standard-approved methodology using FAO data.

The overall GHG reductions achieved by the project activity are then calculated as follows:

$$
E R=\sum B E-\sum P E-\sum L E
$$

Where:

$E R=$ Emission reduction $\left(\mathrm{tCO}_{2} \mathrm{e} /\right.$ year $)$

$B E=$ Baseline emissions for the non PSH $\left(\mathrm{tCO}_{2} \mathrm{e} /\right.$ year $)$

\footnotetext{
${ }^{7}$ Available on http://www.goldstandard.org/wp-content/uploads/2011/10/GS_110411_TPDDTEC_ Methodology.pdf

${ }^{8}$ IPCC, "Energy," in 2006 IPCC Guidelines for National Greenhouse Gas Inventories, vol. 2, 5 vols. (Intergovernmental Panel on Climate Change, 2006).
} 
$P E=$ Project emissions for the $\mathrm{PSH}\left(\mathrm{tCO}_{2} \mathrm{e} /\right.$ year $)$

$L E=$ Leakage $\left(\mathrm{tCO}_{2} \mathrm{e} /\right.$ year $)$

The baseline and project emissions are calculated as follows:

$$
E_{y}=F C_{y} \times\left(\left(f_{N R B, y} \times E F_{f u e l, C O 2}\right)+E F_{f u e l, \text { nonCO2 }}\right) \times N C V_{f u e l}
$$

Where:

$E=$ Emissions for baseline/project situation in $\mathrm{tCO}_{2} \mathrm{e}$

$F C=$ Quantity of fuel consumed for baseline/project situation in tonne

$f_{N R B}=$ Fraction of non-renewable biomass

$N C V_{\text {fuel }}=$ Net calorific value of the fuel that is substituted or reduced

$E F_{\text {fuel,CO2 }}=\mathrm{CO}_{2}$ emission factor of the fuel that is substituted or reduced

$E F_{\text {fuel,non } \mathrm{CO} 2}=$ Non- $\mathrm{CO}_{2}$ emission factor of the fuel that is substituted or reduced

Then, the GHG avoided emission are calculated using the suppressed demand to assess for the impact of a higher comfort in PSH. This requires to build a model linking the non PSH indoor temperature to the level of greenhouse gas emissions and the outdoor HDD18.

To account for the different emission factors of the different used, an Ordinary Least Square regression is developed to link the GHG emission to the indoor temperature for the same outdoor temperature. This model is finally used to estimate the extra GHG emission that would have occurred in non PSH to reach the same indoor temperature level than the $\mathrm{PSH}$ as well as to reach the WHO recommended minimum indoor temperature of $18{ }^{\circ} \mathrm{C}$.

\subsection{Results}

\subsubsection{Energy Efficiency}

\subsubsection{Heating Degrees Day Required to Be at $18{ }^{\circ} \mathrm{C}$ (Outside Temperature)}

In order to compare the average indoor temperature or energy consumption between PSH and non PSH it is necessary to validate that the test conditions are similar, i.e. that there is no significant difference of the cumulative Heating Degree Day necessary to obtain a weekly indoor temperature of $18{ }^{\circ} \mathrm{C}$ between PSH and non PSH (Table 10.1).

Student's $t$-test shows that there is no significant difference between the Heating Degree Day required to be at $18{ }^{\circ} \mathrm{C}$ for PSH and non PSH which indicates that the energy requirement to reach the minimum level of service are the same for the PSH and non PSH groups. 
Table 10.1 Heating Degrees Day for PSH and non PSH

\begin{tabular}{l|l|l}
\hline & Non-PSH & PSH \\
\hline Mean $\left({ }^{\circ} \mathrm{C}\right)$ & $109.69{ }^{\circ} \mathrm{C}$ & $109.19{ }^{\circ} \mathrm{C}$ \\
\hline Standard deviation & 15.36 & 14.95 \\
\hline Coefficient of variation & 0.14 & 0.14 \\
\hline Standard error & 2.13 & 2.53 \\
\hline Uncertainty of the mean $(90 \%$ confidence interval) & 0.03 & 0.04 \\
\hline Conclusion & $\begin{array}{l}\text { The level of precision }( \pm 10 \%) \text { for a } 90 \% \\
\text { confidence interval is met }\end{array}$ \\
\hline
\end{tabular}

\subsubsection{Energy Savings}

For the two groups, firewood was the main fuel consumed, representing approximately the two-thirds of the energy consumption for heating purpose. The remaining energy consumed was a mix of coal, sawdust, cow dung, husk and cardboard. This fuel mix is representative of the energy consumption patterns of Kabul according to the SEADEP results (Fig. 10.2).

The results of the analysis of the energy consumption of the monitored room over the 8 weeks monitoring period are presented in the Table 10.2.

The PSH energy consumption was $23 \%$ lower than non-PSH houses, with a net energy consumption decrease of $60 \mathrm{kWh}$ per week in average (Fig. 10.3). Extrapolated to 1 year considering 110 heating days that represents a saving of $938 \mathrm{kWh}$ per year for each house equipped with PSH.

\subsubsection{Indoor Temperature}

The analysis of the temperature recorded in the main heated room, attached to the veranda for the $\mathrm{PSH}$, during the monitoring period shows the following results (Table 10.3).

Over the monitoring period, the PSH reached an average weekly indoor temperature of $18.22{ }^{\circ} \mathrm{C}$. The PSH average temperature is $8 \%$ higher than non-PSH houses, with a net increase of $1.43{ }^{\circ} \mathrm{C}$ of the weekly indoor average temperature. The variation of the PSH indoor temperature was also much lower than the non PSH (Fig. 10.4).

This difference show that, in addition of reducing fuel consumption, the PSH group reached the WHO recommended minimum indoor temperature of $18^{\circ} \mathrm{C}$. 


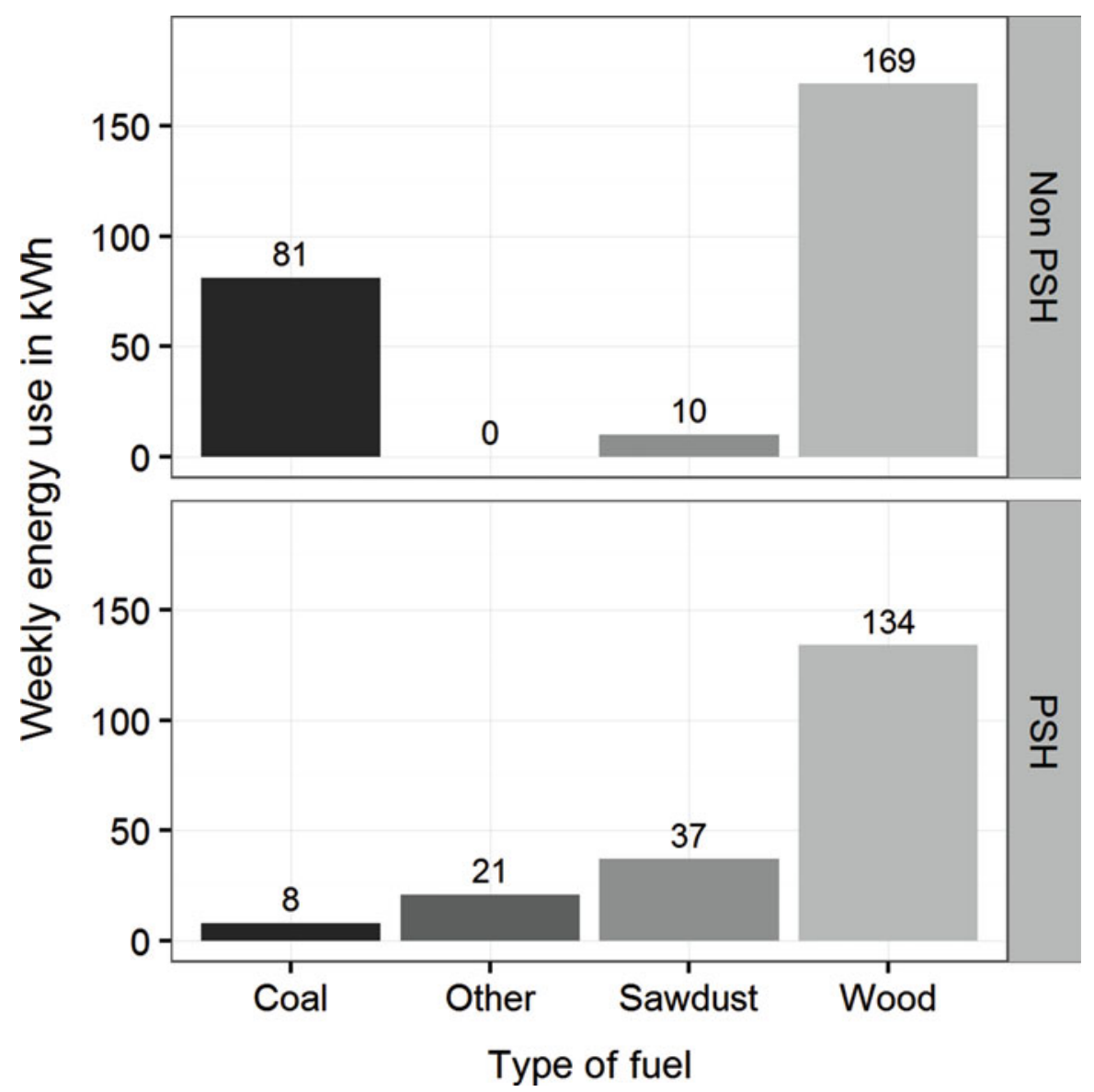

Fig. 10.2 Fuel mix of the PSH and non PSH groups

Table 10.2 Energy consumption of PSH and non PSH

\begin{tabular}{l|l|l}
\hline & Non-PSH & PSH \\
\hline Mean (kWh/week) & 259.76 & 200.05 \\
\hline Standard deviation & 120.73 & 56.47 \\
\hline Coefficient of variation & 0.46 & 0.27 \\
\hline Standard error & 16.74 & 9.55 \\
\hline Uncertainty of the mean (90\% confidence interval) & 0.11 & 0.10 \\
\hline Conclusion & $\begin{array}{l}\text { The level of precision ( } \pm 10 \%) \text { for a 90\% } \\
\text { confidence interval is met for the PSH } \\
\text { group }\end{array}$ \\
\hline
\end{tabular}




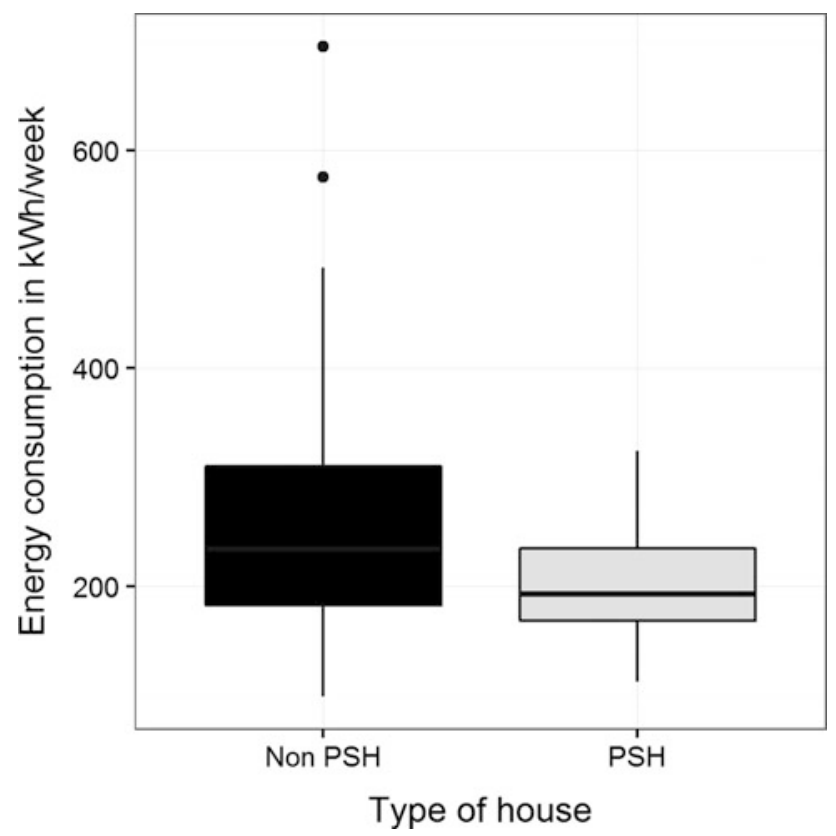

Fig. 10.3 Comparison of the energy consumption between PSH and non-PSH houses

Table 10.3 Indoor temperature of PSH and non PSH

\begin{tabular}{l|l|l}
\hline & Non-PSH & PSH \\
\hline Mean & $16.78{ }^{\circ} \mathrm{C}$ & $18.22{ }^{\circ} \mathrm{C}$ \\
\hline Standard deviation & 3.54 & 1.38 \\
\hline Coefficient of variation & 0.21 & 0.08 \\
\hline Standard error & 0.49 & 0.23 \\
\hline Uncertainty of the mean (90\% confidence interval) & 0.05 & 0.02 \\
\hline Conclusion & $\begin{array}{l}\text { The level of precision }( \pm 10 \%) \text { for a } 90 \% \\
\text { confidence interval is met }\end{array}$ \\
\hline
\end{tabular}

\subsubsection{Greenhouse Gas Emission Reduction and Avoided Emissions}

The emission reduction are calculated based on the recorded actual energy consumption for both the non PSH and PSH. The results extrapolated for the whole winter season considering 110 days of heating are presented in the following table (Table 10.4).

These results show an emission reduction potential from the PSH technology of $0.366 \mathrm{tCO}_{2} \mathrm{e} /$ year. However this does not take into account the higher indoor temperature in the PSH compare to non PSH and the emissions avoided using the PSH technology. 


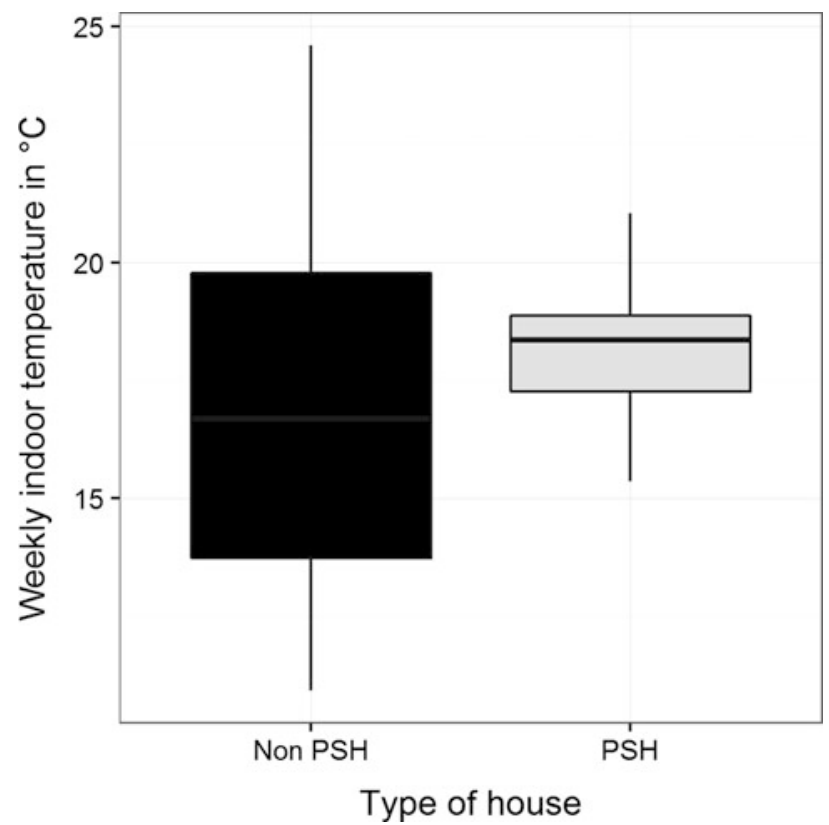

Fig. 10.4 Comparison of the weekly indoor temperature between PSH and non-PSH

Table 10.4 GHG emission per type of house and sampling in $\mathrm{tCO}_{2} \mathrm{e}$

\begin{tabular}{l|l|l}
\hline Non PSH & PSH & Emission reduction \\
\hline 1.414 & 1.049 & 0.366 \\
\hline
\end{tabular}

To assess the avoided emissions of the PSH it is necessary to assess what would have been the additional GHG emissions to reach the same indoor temperature in non PSH. For that, an OLS regression model is developed to assess the relation between the indoor temperature and the GHG emission considering a similar outdoor temperature between non PSH and PSH. For the purpose of this study a simplified model is developed linking the GHG emission and the outdoor temperature to the indoor temperature (Fig. 10.5).

Based on the model developed the avoided emission from the PSH technology if the non PSH household were reaching the same indoor temperature as well as the total climate change mitigation impact are calculated for the whole winter season and presented in the Table 10.5.

The difference between the emission reduction and the avoided emission is significant. This is explained by the fact that PSH indoor temperature was significantly higher than non PSH despite the lower energy consumption. In that case, accounting to avoided emissions led to an impact $110 \%$ higher than accounting for actual emission reduction only.

Another option for calculating the avoided emission is to take the WHO recommended minimum indoor temperature as the minimum service level instead 


\begin{tabular}{|c|c|c|c|c|}
\hline \multicolumn{5}{|c|}{ Regression formula } \\
\hline \multicolumn{5}{|c|}{ Indoor average temperature $=\mathbf{f}(\mathrm{GHG}$ emissions + HDD Outside $)$} \\
\hline \multicolumn{5}{|c|}{ Coefficients } \\
\hline Parameter & Estimate & Standard Error & $t$ value & p value \\
\hline (Intercept) & 21.66 & 2.34 & 9.27 & $2.36 \mathrm{e}-12$ \\
\hline GHG & 0.06 & 0.007 & 7.735 & $4.87 e-10$ \\
\hline HDDOut & -0.09 & 0.02 & -4.499 & $4.20 \mathrm{e}-05$ \\
\hline
\end{tabular}

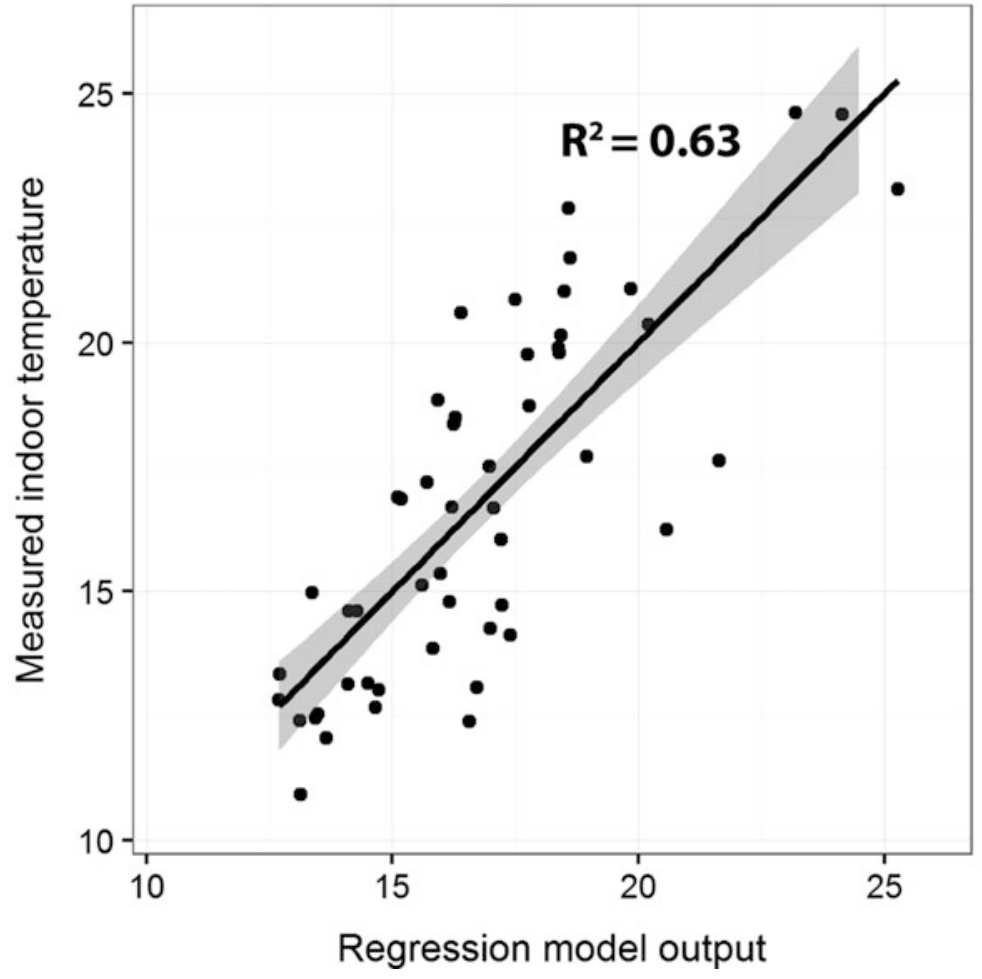

Fig. 10.5 Results of the suppressed demand OLS regression model

Table 10.5 Emission reduction and avoided emission to reach the PSH indoor temperature

\begin{tabular}{l|l}
\hline & $\mathrm{tCO}_{2} \mathrm{e}$ emissions \\
\hline Emission reduction & 0.366 \\
\hline Avoided emission & 0.402 \\
\hline Total impact & 0.768 \\
\hline
\end{tabular}

of the PSH indoor temperature. In this case, considering a minimum service level of $18{ }^{\circ} \mathrm{C}$ instead of the $\mathrm{PSH}$ indoor temperature, the avoided emission are slightly lower with $0.344 \mathrm{tCO}_{2} \mathrm{e}$, but still significant with an increase of the emission reduction by $94 \%$ as describe in Table 10.6. 
Table 10.6 Emission reduction and avoided emission to reach the WHO recommended minimum indoor temperature

\begin{tabular}{l|l}
\hline & $\mathrm{tCO}_{2} \mathrm{e}$ emissions \\
\hline Emission reduction & 0.366 \\
\hline Avoided emission & 0.344 \\
\hline Total impact & 0.709 \\
\hline
\end{tabular}

Overall, using both minimum service level, the avoided emissions represent approximately half of the total climate change mitigation impact of the PSH technology.

\subsection{Implication for Policy Makers and Development Practitioners}

This study shows that accounting for the suppressed demand can have a significant impact on the climate change mitigation potential of a project with strong social improvement components. With a fuel savings of $23 \%$, the PSH technology contributes to reduce the households vulnerability during winter period when the source of income is the most irregular and the expenses are at the highest level. Equally important, the veranda increases significantly the indoor temperature in the main family room during the cold winter bringing health and confort benefits. To assess the full benefits of this technology it is therefore necessary to account for avoided emissions in addition of emission reductions.

The avoided emissions from increase in indoor temperature with the PSH represented approximately the same amount than actual emission reductions from reduced fuel consumption. This could indicate that the household balance the reduction in fuel expenses when their financial vulnerability is the highest and the increase in indoor temperature during the coldest period of the year. The barrier to reach the minimum service level being financial, it reinforces the relevance of applying a suppressed demand approach to account for household preferences and therefore comprehensively assess the climate change impact of a project.

In this case study, two minimum service levels have been considered: the indoor temperature reached using the PSH technology, as well as the WHO recommended minimum indoor temperature. With an average weekly indoor temperature of $18.22{ }^{\circ} \mathrm{C}$, considering the $\mathrm{PSH}$ indoor temperature or the $\mathrm{WHO}$ recommended value of $18{ }^{\circ} \mathrm{C}$ as minimum service level leads to marginal differences in avoided 
emissions. However in other contexts, differences between recommended values and real achievement might be much higher. In such cases the level to be accounted for the suppressed demand should be, whenever possible, the level achieved using the technology or practices introduced, as long as it doesn't exceed the agreed minimum service level.

Linking differences in services levels to greenhouse gases emission may represent the major challenge to include the suppressed demand in climate change mitigation evaluations. This evaluation used a simple linear regression model to assess the suppressed demand. With an important work on the sampling, the sources of variation have been minimized which allowed to achieve relatively good coefficient of determination considering the simplicity of the model. But this model suffer from strong limitations and very low external validity. In the future, considering the important limits of the OLS to model the indoor temperature, the development of context specific dynamic thermal models appears as a relevant option to account for the suppressed demand. However, housing conditions are heterogenious in characteristics and therefore the model should be adaptable to a wide number of houses using parameters that could be easily collected. Alternatively, default factors of energy consumption could be developed to assess the baseline emission levels for different levels of indoor temperature.

Applying the suppressed demand also requires important data collection and significant equipment in the case of temperature monitoring. In the PSH case study, the potential factors of variation between the houses are very important which require a very carefull sampling. This study rely on an important household survey as well as highly trained surveyors to assess the houses characteristics and select the samples. In difficult contexts like Afghanistan undertaking long house intrusive surveys comes with numerous challenges in terms of social acceptation and cost in comparison of the budget for project implementation. To insure a high quality of analysis, fuel consumption measurements had to be done 5 days a week during 8 weeks. In the Afghan context, the fact that a man cannot enter in a house when a woman is alone and the security context of Kabul have strongly affected the study. This led to numerous visits to the same household to gather data and in some cases can lead to withdrawing some houses from the study.

Despite a limited immediate climate change mitigation potential, the investment in energy efficient housing is crutial to achieve a low-carbon pathway and avoid a critical carbon locking considering the time frame of housing investment. Future research should focus on the development of suppressed demand models that could be adaptable to different contexts. Emission default factors accounting for both emission reductions and avoided emissions could help decision-making on climate change mitigation policies by highlighting the significance of the emissions that would result from long-term investments in carbon-intensive technologies. In LDCs, successful climate change mitigation action requires to anticipate the socio-economic development that will lead to investment in carbon-intensive 
infrastructures or practices. The generalization of the suppressed demand in the project screening procedures for climate financing and project evaluation methodologies can contribute significantly to meet both climate change mitigation objectives and Sustainable Development Goals.

Open Access This chapter is distributed under the terms of the Creative Commons AttributionNonCommercial 4.0 International License (http://creativecommons.org/licenses/by-nc/4.0/), which permits any noncommercial use, duplication, adaptation, distribution and reproduction in any medium or format, as long as you give appropriate credit to the original author(s) and the source, provide a link to the Creative Commons license and indicate if changes were made.

The images or other third party material in this chapter are included in the work's Creative Commons license, unless indicated otherwise in the credit line; if such material is not included in the work's Creative Commons license and the respective action is not permitted by statutory regulation, users will need to obtain permission from the license holder to duplicate, adapt or reproduce the material. 